\title{
DEVELOPMENT AND VALIDATION OF A STABILITY-INDICATIVE AGAR DIFFUSION ASSAY TO DETERMINE THE POTENCY OF FLUCLOXACILLIN SODIUM IN CAPSULES
}

\section{FLÁVIA A.M. FIORENTINO* AND HÉRIDA R.N. SALGADO}

Post Graduation Program in Pharmaceutical Sciences, School of Pharmaceutical Sciences, Univ. Estadual Paulista, Araraquara, SP, Brazil. *Corresponding Author: Email- flafiorentino@ig.com.br

\begin{abstract}
Flucloxacillin sodium (FLU) is a semi-synthetic penicillin active against many gram-positive bacteria such as streptococci and penicilinase-producing staphylococci, including methicillin-susceptible $S$. aureus. This study describes the development and validation of a microbiological assay, applying the diffusion agar method for the determination of FLU, as well as the evaluation of the ability of the method in determining the stability of FLU in capsules against acidic and basic hydrolysis, photolytic and oxidative degradations, using $S$. aureus ATCC 25923 as micro-organism test and $3 \times 3$ parallel line assay design (three doses of the standard and three doses of the sample in each plate), with six plates for each assay, according to the Brazilian Pharmacopoeia. The validation method showed good results including linearity, precision, accuracy, robustness and selectivity. The assay is based on the inhibitory effect of FLU using Staphylococcus aureus ATCC 25923. The results of the assay were treated by analysis of variance (ANOVA) and were found to be linear $(r=0.9997)$ in the range from 1.5 to $6.0 \mu \mathrm{g} / \mathrm{mL}$, precise (repeatability: R.S.D. $=1.63$ and intermediate precision: R.S.D. $=1.64$ ) and accurate $(98.96 \%)$. FLU solution (from the capsules) exposed to direct UVC light $(254 \mathrm{~nm})$, alkaline and acid hydrolysis and hydrogen peroxide causing oxidation were used to evaluate the specificity of the bioassay. Comparison of bioassay and liquid chromatography by ANOVA showed no difference between methodologies. The results demonstrated the validity of the proposed bioassay, which is a simple and useful alternative methodology for FLU determination in routine quality control.
\end{abstract}

Key words- Flucloxacillin, Bioassay, Penicillin, Pharmaceutical formulation, Quality control, Validation.

Citation: Flávia A.M. Fiorentino and Hérida R.N. Salgado (2012) Development and Validation of a Stability-Indicative Agar Diffusion Assay to Determine the Potency of Flucloxacillin Sodium in Capsules. International Journal of Microbiology Research, ISSN: 0975-5276 \& EISSN:0975-9174, Volume 4, Issue 4, pp.-217-222.

Copyright: Copyright@2012 Flávia A.M. Fiorentino and Hérida R.N. Salgado. This is an open-access article distributed under the terms of the Creative Commons Attribution License, which permits unrestricted use, distribution, and reproduction in any medium, provided the original author and source are credited.

\section{Introduction}

Flucloxacillin (FLU) is a semi-synthetic and penicillinase-stable isoxazolyl penicillin active against many Gram-positive bacteria such as hemolytic streptococci and penicillinase-producing staphylococci, including methicillin-susceptible $S$. aureus (MSSA), but not active against methicillin-resistant $S$. aureus. It acts by the inhibition of transpeptidation, thus leading to the formation of a weakened peptidoglycan. As autolysins continue to act, the cell walls of Gram-positive organisms become progressively weaker, and osmotic lysis takes place [1,2]. FLU is chemically known as sodium (2S,5R,6R)-6-[[[3-(chloro-6-fluorophenyl)-5-methylisoxazol -4-yl]carbonyl]amino]-3,3-dimethyl-7-oxo-4-thia-1-azabicyclo [3.2.0]hepatane - 2 carboxylate monohydrate [3-5]. FLU is used for the treatment of skin, soft tissue and respiratory tract infections as well as endocarditis and osteomyelitis caused by methicillinsusceptible $S$. aureus [2]. The chemical structure of FLU sodium is presented in (Fig. 1).<smiles>Cc1onc(-c2c(F)cccc2Cl)c1C(=O)N[C@H]1C(=O)N2C1SC(C)(C)C2C(N)=O</smiles>

Fig. 1- Chemical structure of flucloxacillin sodium (CAS 1847-241). 
This antibiotic is officially recognized in the Portuguese, European and British pharmacopoeias [3-5], and they provide the liquid chromatography with UV spectrophotometric detection as the assay for flucloxacillin sodium in bulk. Moreover, the British pharmacopoeia [4] describes the same method to assay flucloxacillin sodium in the pharmaceutical form of capsules. The literature describes several methods to analyze FLU in different pharmaceutical dosage forms, including visible spectrophotometric [6-13], UV spectrophotometric [14] and HPLC methods [15-16]. The literature also reports methods to analyze FLU and its degradation products by HPLC [17] or RMN methods [18] and microbiological assay for biological fluids [19-23]. However, a microbiological assay to determine FLU in capsules has not been reported yet. Moreover, it allows the potency of FLU to be assessed, which is very important for the analysis of antibiotics.

The development of alternative analytical methodologies, such as a simple, operationally inexpensive microbiological assay using agar diffusion for antibiotics, represents a great advantage for quality control laboratories not equipped with specialized and sophisticated instruments. However, the low cost and simple procedures of bioassays have allowed them to become an alternative methodology for drug potency assessment in pharmaceutical formulations [24-25]. This assay can reveal subtle changes not demonstrable by conventional chemical methods such as biological activity. Biossay is an ecological technique because it is not produces residue or solvent. Also sometimes, microbiological assay might be a technique as sensitive as the chromatographic method, but has no need to use organic solvents for their implementation [25-29].

The aim of this study was to develop and validate a simple, sensitive, precise, accurate and stability-indicative microbiological assay by agar diffusion to quantify FLU in capsules as an alternative to the physicochemical method described in the literature. Moreover, a high performance liquid chromatographic (HPLC) method, developed and validated previously for our study group, was chosen as a comparison method to determine FLU in degraded samples.

\section{Materials and Methods \\ Chemicals and reagents}

Flucloxacillin sodium reference substance (assigned purity 90.0\%) was supplied by Glaxo Smith Klane ${ }^{\circledR}$ (England). Flucloxacillin sodium capsules (Floxapen ${ }^{\circledR}$, Actavis Group ${ }^{\circledR}$, Switzerland) claimed to contain $500.0 \mathrm{mg}$ of the active component were purchased in Switzerland. The placebo was prepared in the laboratory using amounts of pharmaceutical grade excipient: magnesium stearate. The qualitative composition of placebo was the same as claimed in Floxapen ${ }^{\circledR} 500 \mathrm{mg}$. Ultrapure water was obtained from a Milli$\mathrm{Q}^{\circledR}$ Plus apparatus (Millipore ${ }^{\circledR}, \mathrm{USA}$ ) and it was used to prepare all solutions for the bioassay and HPLC methods. All chemical used were of analytical grade and all solvents were of HPLC grade. Methanol was purchased from J.T. Backer ${ }^{\circledR}$ (Mexico), phosphoric acid was obtained from Berzog ${ }^{\circledR}$ (Germany), dibasic potassium phosphate, monobasic potassium phosphate were purchased from Vetec ${ }^{\circledR}$ (Brazil), sodium hydroxide was obtained from Synth ${ }^{\circledR}$ (Brazil) and hydrochloric acid was obtained from Synth ${ }^{\circledR}$ (Brazil). Antibiotic medium number 1 agar was obtained from Difco ${ }^{\circledR}$ (USA), typic soy agar was purchase from Acumedia $^{\circledR}$ (USA) and Brain
Hearth Infusion (BHI) broth was purchase from Acumedia ${ }^{\circledR}$ (USA). Magnesium stearate pharmaceutical grade was acquired from Audaz Farmacopeia Fina ${ }^{\circledR}$ (Brazil).

\section{Apparatus}

Photodegradation studies were carried out in a photostability UV chamber with mirrors equipped with a UVC lamp (254 nm), and UV cuvettes were employed as containers for the samples. A digital caliper (Mitutoyo ${ }^{\circledR}$, Japan) was utilized to measure the diameters in the zone of growth inhibition (mm). For $\mathrm{pH}$ measurement, a digital pHmeter (Micronal ${ }^{\circledR} 474$, Brazil) was used.

An LC system consisting of Waters ${ }^{\circledR}$, model 1525 (Waters Chromatography systems, CA, USA) was connected to a UV/Visible Waters 2487 and an injector fitted Rheodyne Breeze 7725i with a $20 \mu \mathrm{L}$ loop. The chromatographic separation was carried out under isocratic reversed-phase conditions on an Agilent Zorbax ${ }^{\circledR}$ C18 column, $5 \mu \mathrm{m}, 4.6$ × $250 \mathrm{~mm}$ (Agilent ${ }^{\circledR}$, Santa Clara, CA, USA). The mobile-phase consisted of methanol and $0.025 \mathrm{M}$ phosphoric acid adjusted to $\mathrm{pH} 5.5(60: 40 ; \mathrm{v} / \mathrm{v})$. The analyses were done at a flow-rate of $1.0 \mathrm{~mL} \mathrm{~min}^{-1}$, using a UV-VIS detector at $225 \mathrm{~nm}$ and at room temperature.

\section{Preparation of standard solutions}

An accurately weight amount of powder equivalent to $10 \mathrm{mg}$ of FLU reference standard was transferred to $100 \mathrm{~mL}$ volumetric flask and ultrapure water was added to fill up the volume, obtaining a solution at concentration of $100 \mu \mathrm{g} \mathrm{mL}^{-1}$. Aliquots of this solution were diluted in potassium phosphate buffer solution $\mathrm{pH}$ 6.0 to obtain the concentrations of $1.5 ; 3.0$ and $6.0 \mu \mathrm{gL} \mathrm{m}^{-1}$ (S1, S2 and S3, respectively), which were used in the bioassay.

\section{Preparation of sample solutions}

Twenty capsules were weighed and the powder was mixed. An amount of powder equivalent to $10 \mathrm{mg}$ of flucloxacillin sodium was transferred to a $100 \mathrm{~mL}$ volumetric flask and ultrapure water was added to fill up the volume, obtaining a solution at concentration of $100 \mu \mathrm{g} \mathrm{mL}-1$. Aliquots of this solution were diluted in potassium phosphate buffer solution $\mathrm{pH} 6.0$ to obtain the concentrations of 1.5; 3.0 and $6.0 \mu \mathrm{g} \mathrm{mL}^{-1}$ (T1, T2 and T3 respectively), which were tested against $\mathrm{S} 1, \mathrm{~S} 2$ and $\mathrm{S} 3$.

\section{Microorganism and inoculums}

The strain of Staphylococcus aureus ATCC 25923 were cultivated and maintained on tryptic soy agar medium in the freezer and pealed to $\mathrm{BHI}$ broth ( $24 \mathrm{~h}$ before the assay) that was kept at $35 \pm 2$ ${ }^{\circ} \mathrm{C}$. The microorganism standardization was made according to the procedure described in the Brazilian and The United States Pharmacopoeias [30-31]. The bacteria, previously incubated in $\mathrm{BHI}$ broth, were diluted with $\mathrm{BHI}$ broth to achieve a suspension turbidity of $25 \pm 2 \%$ (transmittance) using a spectrophotometer (Beckman, DU ${ }^{\circledR} 530$ ) with the wavelength at $580 \mathrm{~nm}$ and a $10 \mathrm{~mm}$ absorption cell, against BHI broth as blank. Aliquots of $1.0 \mathrm{~mL}$ of this standardized suspension were added to each $100 \mathrm{~mL}$ of antibiotic medium number 1 agar at $47 \pm 1^{\circ} \mathrm{C}$ and it was used as the inoculated layer in the plate.

\section{Agar diffusion bioassay}

The bioassay describe followed the $3 \times 3$ parallel line assay de- 
sign (three doses of the standard and three doses of the sample in each plate), with six plates for each assay, according to the Brazilian Pharmacopoeia [30]. The agar was composed of two separate layers (a base layer and another layer containing the inoculum). The antibiotic medium number 1 agar $(20 \mathrm{~mL})$ was poured into a $100 \mathrm{~mm} \times 20 \mathrm{~mm}$ Petri dish as a base layer. After the solidification, portion of $5 \mathrm{~mL}$ of inoculated antibiotic medium number 1 agar was poured onto the base layer. In each plate, a template was placed on the surface of the inoculated medium. Three alternated holes were filled with $200 \mu \mathrm{L}$ of the reference solution (S1, S2 and S3), and the other three holes were filled with the sample solutions (T1, T2 and T3). Six plates were used to each assay. The plates were incubated at $35 \pm 1{ }^{\circ} \mathrm{C}$ aerobically for 18 hours. The zone diameters $(\mathrm{mm})$ of the growth inhibition were carefully measured using a digital caliper. All experiments were performed in a biological safety cabinet and the infected material was decontaminated before being discarded and all safety procedures (wearing masks, gloves and cap) were adopted.

\section{Method validation}

The method was validated by determination of the following operational characters: linearity, precision, accuracy and robustness [24-29, 31-34].

Linearity- in order to assess the validity of the assay, three doses of the reference substance were used. The linearity was evaluated by linear regression analysis, which was calculated by the least squares method.

Precision- the precision of the method was determined by repeatability and intermediate precision and was expressed as the relative standard deviation (RSD). Repeatability (intra-assay) was examined by assaying samples of capsules, at the same concentration within 1 day and under the same experimental conditions. The intermediate precision was evaluated by comparing the assays on 3 different days (inter-assay).

Accuracy- the accuracy was determined by adding known amounts of FLU reference substance to the sample solutions. Accurately weighed amount of capsules equivalent of $10 \mathrm{mg} \mathrm{FLU}$ was transferred to a $100 \mathrm{~mL}$ volumetric flask and dissolved in ultrapure water $\left(100 \mu \mathrm{g} \mathrm{mL}^{-1}\right)$. Aliquots of $200 \mu \mathrm{L}$ were transferred to 3 volumetric flasks, obtaining R1, R2 and R3, respectively. Aliquots of 40,100 and $160 \mu \mathrm{L}$ of reference standard solution at concentration $100 \mu \mathrm{g} \mathrm{mL}-1$, were transferred to R1, R2 and R3, respectively. The volume was filled up with potassium phosphate buffer solution $\mathrm{pH} 6.0$, obtaining final concentrations of 2.4, 3.0 and $3.6 \mathrm{\mu g} \mathrm{mL}^{-1}$ that correspond to 80,100 and $120 \%$ of the medium concentration. The percentage recovery of FLU reference substance added was calculated using the formula proposed by the AOAC [33].

Specificity- the ability of the proposed method to determine FLU in the presence of degradation products was assessed by comparing the results obtained from the degraded samples analyzed by bioassay and by HPLC method (developed and validated in the previous studies). Under all conditions, the sample solutions were assayed and compared to freshly prepared FLU reference substance solutions at the same theoretical concentrations. Specificity was also checked using the excipient of the formulation to determine whether this substance could interfere with the assay. The preparations of the degraded FLU and excipient solutions were the following.
- Acid hydrolysis: the sample solutions were prepared and maintained in $0.001 \mathrm{M} \mathrm{HCl}$ for $4 \mathrm{~h}$ and stored at room temperature. After that, aliquots of these solutions $(100 \mu \mathrm{g} \mathrm{mL}-1)$ were removed, neutralized with $0.01 \mathrm{M} \mathrm{NaOH}$ and diluted in potassium phosphate buffer solution $\mathrm{pH} 6.0$ to achieve theoretical concentrations of $1.5,3.0$ and $6.0 \mu \mathrm{gL} \mathrm{m}^{-1}$.

- Basic hydrolysis: the sample solutions were prepared and maintained in $0.001 \mathrm{M} \mathrm{NaOH}$ for $3 \mathrm{~h}$ and stored at room temperature. After that, aliquots of these solutions $\left(100 \mu \mathrm{g} \mathrm{mL}^{-1}\right)$ were removed, neutralized with $0.01 \mathrm{M} \mathrm{HCl}$ and diluted in potassium phosphate buffer solution $\mathrm{pH} 6.0$ to achieve theoretical concentrations of $1.5,3.0$ and $6.0 \mu \mathrm{g} \mathrm{mL}^{-1}$.

- Oxidative degradation: the sample solutions were prepared and maintained in a $1 \% \mathrm{H}_{2} \mathrm{O}_{2}$ solution and stored at room temperature for 30 minutes. After that, aliquots of these solutions $(100 \mu \mathrm{g} \mathrm{mL}-1)$ were removed and diluted in potassium phosphate buffer solution $\mathrm{pH} 6.0$ to achieve theoretical concentrations of $1.5,3.0$ and $6.0 \mu \mathrm{g} \mathrm{mL}-1$.

- Photodegradation: aqueous sample solution (100 $\mu \mathrm{g} \mathrm{mL}-1)$ was exposed to UVC lamp ( $254 \mathrm{~nm})$ for $1 \mathrm{~h}$. The stress degradation study was performed exposing the solution in quartz cell in the photodegradation chamber, where the sample was positioned horizontally to provide maximum area of exposure to the light source. After that, this solution were removed and diluted in potassium phosphate buffer solution $\mathrm{pH} 6.0$ to achieve theoretical concentrations of $1.5,3.0$ and $6.0 \mu \mathrm{g} \mathrm{mL}^{-1}$.

- Excipients: the amount of formulation excipient containded in $10 \mathrm{mg}$ FLU capsules was accurately weighed and dissolved in a $100 \mathrm{~mL}$ volumetric flask with ultrapure water. The same aliquots used to prepare the sample solutions were withdrawn and diluted in potassium phosphate buffer solution $\mathrm{pH}$ 6.0.

Robustness- the robustness of the method was determined by analyzing the same ample under a variety of conditions. The considered factors were incubation time and volume of the inoculated layer (thickness). The variation of the mean diameter of the inhibition zones between the different assays was statistically analyzed by Student $t$ test.

\section{Calculation}

To calculate the activity of FLU, the Hewitt equation was used [35]. The assays were calculated statistically by the linear parallel model and regression analysis and verified using analysis of variance (ANOVA).

\section{HPLC method}

An LC system consisting of Waters ${ }^{\circledR}$, model 1525 (Waters ${ }^{\circledR}$ Chromatography system, CA, USA) was connected to a UV/Visible Waters ${ }^{\circledR} 2487$ and an injector fitted Rheodyne Breeze ${ }^{\circledR} 7725$ i with a $20 \mu \mathrm{L}$ loop. The chromatographic separation was carried out under isocratic reversed-phase conditions on a Agilent Zorbax ${ }^{\circledR}$ C18 column, $5 \mu \mathrm{m}, 250 \mathrm{~mm} \times 4.6 \mathrm{~mm}$ (Agilent ${ }^{\circledR}$ ). The mobile phase consisted of methanol and phosphoric acid $0.025 \mathrm{M}$ adjusted to $\mathrm{pH} 5.5(60: 40 ; \mathrm{v} / \mathrm{v})$. The run at a flow-rate of $1.0 \mathrm{~mL} \mathrm{~min}^{-1}$, using a UV-VIS detector at $225 \mathrm{~nm}$ and the run time was $4.4 \mathrm{~min}$. The temperature was set at room temperature.

\section{Comparison of methods}

The results obtained in this study were compared with those by a 
high-performance liquid chromatography (HPLC) method described previously. The methods were statistically

analyzed using the analysis of variance (ANOVA), which indicates whether there is a significant difference between these methods at a $5 \%$ significance level.

\section{Results}

\section{Method validation}

Linearity- the results of growth inhibition zone diameter of FLU reference substance are shown in Table 1. The results of growth inhibition zone diameter of FLU reference substance are shown in Fig. 2. The calibration curve for FLU (Fig. 3) was constructed by plotting zone diameter $(\mathrm{mm})$ versus log of concentration $(\mu \mathrm{g} \mathrm{mL}-1)$ and showed good linearity between 1.5 and $6.0 \mu \mathrm{g} \mathrm{mL}^{-1}$ range. The representative linear equation for FLU was $y=5.668 \mathrm{Ln}(x)+$ 19.486 , where $x$ is log dose and $y$ is zone diameter. The correlation coefficient ( $r=0.9997$ ) was highly significant for the method and there were no deviations from parallelism and linearity with the obtained results $(P<0.05)$.

Table 1-Diameters of growth inhibition zone for flucloxacillin sodium reference substance solution obtained for standard curve

\begin{tabular}{|c|c|c|c|}
\hline $\begin{array}{l}\text { Concentration, } \\
\mu \mathrm{g} / \mathrm{mL}\end{array}$ & $\begin{array}{l}\text { Range of } \\
\text { zone size, } \\
\mathrm{mm}\end{array}$ & $\begin{array}{l}\text { Mean diameters of } \\
\text { growth inhibition } \\
\text { zones }^{\mathrm{a}} \mathrm{mm}\end{array}$ & RSD \% \\
\hline 1.5 & $21.56-21.83$ & 21.74 & 0.6 \\
\hline 3.0 & $25.45-26.04$ & 25.81 & 1.0 \\
\hline 6.0 & $29.20-29.79$ & 29.59 & 1.0 \\
\hline
\end{tabular}

a Each value is the mean of six plates.

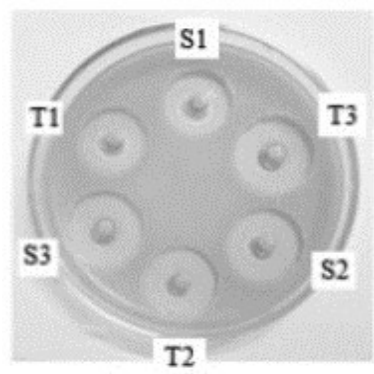

Fig. 2- Agar diffusion assay using a strain of $S$. aureus ATCC 25923 as the test microorganism. Flucloxacillin sodium reference solution is at concentrations of 1.5 (S1), 3.0 (S2) and $6.0 \mu \mathrm{g} / \mathrm{mL}$ (S3) and flucloxacillin sodium sample at concentrations of 1.5 (T1), 3.0 (T2) and $6.0 \mu \mathrm{g} / \mathrm{mL}$ (T3).

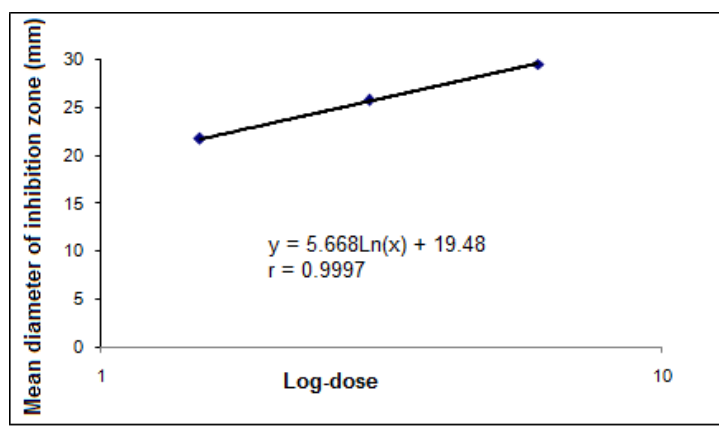

Fig. 3- FLU calibration curve obtained by the microbiological assay
Precision- the method precision in terms of repeatability (intraassay) was evaluated by the determination of sample in the same day, at the same concentration and under the same experimental conditions. The results obtained showed RSD values lower than $1.63 \%$. Intermediate precision was determinate by analyzing the same sample on three different days (inter-assay) and showed RSD lower than $1.65 \%$. The lower RSD values achieved confirm that the proposed method has capacity to generate, for the same sample, reproducible results with low response variation between independent assays. The experimental values obtained for the FLU determined in capsules are presented in Table 2.

Table 2- Inter-assay precision data for the bioassay of flucloxacillin sodium in pharmaceutical formulation

\begin{tabular}{llllll|}
$\begin{array}{l}\text { Sample in } \\
\text { capsules } \\
\text { (mg) }\end{array}$ & Day & $\begin{array}{l}\text { Experimental } \\
\text { amount a } \\
(\mathrm{mg})\end{array}$ & $\begin{array}{l}\text { Potency } \\
\text { found } \\
(\%)\end{array}$ & $\begin{array}{l}\text { Medium } \\
\text { potency } \\
(\%)\end{array}$ & $\begin{array}{l}\text { RSD(\%) } \\
\text { inter-day }\end{array}$ \\
\hline \multirow{2}{*}{500} & 1 & 468.1 & 93.62 & & \\
& 2 & 464.55 & 92.91 & 94.32 & 1.65 \\
\hline
\end{tabular}

a Each value is the mean of six plates.

Accuracy- the accuracy of the method was evaluated by determination of analyte in solutions prepared via the standard addition method. The recovery rates were 99.75, 98.12, 99.00, the mean accuracy was $98.98 \%$ and RSD was $0.82 \%$, which confirms the ability of the method to determine with accuracy the FLU concentration within the range of $80-120 \%$, and shows that the results obtained from the bioassay were close to the true concentration values of the samples.

Specificity- the same degradation conditions used to validate the stability-indicating HPLC method, previously validated in our laboratory, were employed in the microbiological assay.

- Degradation under acidic conditions $(0.001 \mathrm{M} \mathrm{HCl}$ for $4 \mathrm{~h}$ ): the FLU sample solution demonstrated to be unstable by HPLC method and microbiological assay. Under HPLC conditions, the drug concentration decrease about $7.24 \%$. Such instability was also detected during the microbiological assay, when the drug activity decreased about $9.25 \%$ in $0.001 \mathrm{M} \mathrm{HCl}$ for $4 \mathrm{~h}$.

- Degradation under basic conditions $(0.001 \mathrm{M} \mathrm{NaOH}$ for $3 \mathrm{~h})$ : the FLU sample solution demonstrated to be unstable by HPLC method and microbiological assay. Under HPLC conditions, the drug concentration decrease about $42.94 \%$ and by microbiological assay, the drug concentration decrease about $32.06 \%$.

- The oxidative stress conditions: could not be evaluated due to the bactericide activity of the $1 \%$ hydrogen peroxide solution used as the oxidative agent.

- Under photolytic conditions (UVC radiation): the drug concentration decreased about $13.47 \%$ by microbiological assay and, the drug concentration decreased about $2.0 \%$ by HPLC method.

- During the specificity analysis using the formulation excipient: no inhibition zone was formed under the study conditions, revealing the absence of interference from this substance.

Robustness- in order to assess the robustness, some parameters were modified from the normal conditions: incubation time (17 and $19 \mathrm{~h}$ ) and volume of inoculated layer (4.5 and $5.5 \mathrm{~mL})$. The 
quantification of FLU in capsules using the bioassay method can be considered robust because the factor under study did not have a significant effect on the determination of the potency, except the bigger volume of inoculated layer $(5.5 \mathrm{~mL})$ (Table 3$)$.

Table 3- Conditions investigated in the robustness test

\begin{tabular}{|llll|}
\hline Condition & Parameter & $\mathrm{t}_{\text {cal }}$ & $\mathrm{t}_{\text {tab }}$ \\
\hline Incubation time & $17 \mathrm{~h}$ & 2.13 & 2.23 \\
volume of inoculated layer & $19 \mathrm{~h}$ & 2.00 & 2.23 \\
& $4.5 \mathrm{~mL}$ & 0.82 & 14.5 \\
& $5.5 \mathrm{~mL}$ & 2.23 & 2.23 \\
\hline
\end{tabular}

\section{Comparison of the methods}

The results obtained in this study were comparable with those obtained by HPLC (Table 4). For the microbiological assay method, the mean potency found was $94.32 \% \pm 1.98 \%$ and for HPLC method, $94.02 \% \pm 1.11 \%$. These results were statistically analyzed using analysis of variance and indicated that there was no significant differences between the methods at $\alpha=0.05\left(F_{\text {calculated }}\right.$ $\left.0.06<F_{\text {theoretical }} 7.70\right)$. Therefore, the methods developed and validated provided similar results for FLU quantitation in capsules. Moreover, potency results were within the pharmacopeial limits of $92.5-110.0 \%$ for FLU in capsules [4].

Table 4- Assay results of flucloxacillin sodium by 2 different methods

\begin{tabular}{|lllll|}
\hline Day & $\begin{array}{l}\text { Liquid } \\
\text { chromatography }(\%)^{\mathrm{a}}\end{array}$ & $\begin{array}{l}\text { Mean } \\
(\%)\end{array}$ & $\begin{array}{l}\text { Microbiological } \\
(\%)\end{array}$ & $\begin{array}{l}\text { Mean } \\
(\%)\end{array}$ \\
\hline 1 & 92.81 & 93.62 & 94.32 \\
2 & 94.72 & 94.02 & 92.91 & 96.42 \\
3 & 94.53 & & 96.42 & \\
\hline
\end{tabular}

a Means of three replicates

\section{Discussion}

Biological methods are advantageous because the measured parameter and the therapeutic properties of the drug are the same. Therefore, microbiological or biological assays remain, in general, the standard for dispelling doubts about the potential loss of activity [24, 36].

The development and validation of analytical methods for the potency determination has received considerable attention recently, mainly from regulatory agencies, because of their importance in pharmaceutical analysis $[25,26,28,29,33]$. For this reason, a microbiological assay was proposed as a suitable method for the determination of FLU in capsules.

The potency of an antibiotic may be demonstrated under suitable conditions by comparing the growth inhibition of sensitive microorganisms produced by known concentrations of the antibiotic to be studied and a reference standard [5, 30, 31]. In this experimental work a $3 \times 3$ design, using three levels for each standard and sample solutions were used following the procedure described in the Brazilian Pharmacopoeia [30]. The calculation procedure normally assumes a direct relationship between the observed diameter of the inhibition zone and the logarithm of the applied dose.

The experimental conditions were adjusted to accurately determine the performance of the assay. Some parameters were tested earlier to stablish the conditions described. The microorganism tested were Staphylococcus epidermidis ATCC 12228 IAL 2150,
Staphylococcus aureus ATCC 25923 and Micrococcus luteus ATCC 9341 IAL 636. The strain of Staphylococcus aureus ATCC 25923 was found to be an appropriate test microorganism because of its sensitivity to FLU and its capacity to form sharply defined inhibition growth zones, allowing measurements with precision. Ultrapure water, potassium phosphate buffer solution $\mathrm{pH}$ 6.0 and 8.0 were tested as solvent for the solution, and the best results were obtained with potassium phosphate buffer solution $\mathrm{pH}$ 6.0. Antibiotic medium 1 and 11 agar were tested and the best results were obtained with Antibiotic medium 1.

Antibiotic assays must be designed in such a way that they allow the mathematical model's validity to be examined based on a potency equation. According to the European, Brazilian and The United States Pharmacopoeias [4, 30, 31], if a parallel-line model is chosen, the two log dose-response lines of the preparations to be examined as well as the reference preparation must be parallel and they must be linear over the range of doses used in the calculation. These conditions must be verified by validity tests for a given probability, usually $P=0.05$. The assays were validated by means of the analysis of variance, as described in these official codes. There were no deviations from parallelism and linearity with the obtained results $(P<0.05)$.

Considering all the stress conditions used to develop and validate both methods, it is possible to conclude that the drug is unstable under photolytic, acid and alkaline conditions. Also, the results suggest that the degradation products formed did not show activity against $S$. aureus, demonstrating that the microbiological assay was specific to determine FLU in capsules.

The quantification of antibiotic components by chemical methods such as HPLC and UV spectrophotometry, although precise, cannot provide a true indication of biological activity. Attempts to correlate antibiotic bioassay results with those from chemical methods have proved disappointing. Therefore, bioassays continue to play an essential role in manufacturing and quality control of antibiotic medicines, and still demand considerable skill and expertise to assure success [24, 25, 27, 29]. Although the biological assays can have a high variability, the analysis of the obtained results demonstrated that the proposed method might be very useful for determination of FLU in capsules.

This work is the first reported validated bioassay for quantification of flucloxacillin and it showed that the procedure might be successfully implemented into routine quality control testing as a good alternative methodology for pharmaceutical analysis of FLU in capsules.

\section{Conclusions}

This method is successfully validated and can be adopted to show stability of compounding pharmaceutical capsules containing flucloxacillin sodium.

The results indicated that the microbiological assay demonstrated good linearity, precision, accuracy, robustness and stabilityindicating at concentrations ranging from 1.5 to $6.0 \mu \mathrm{g} \mathrm{mL}^{-1}$, therefore, being acceptable alternative method for the routine quality control of FLU in capsules. Moreover, there is no statistically difference between the microbiological assay and HPLC method (developed and validated in a previous study) for drug quantification, therefore, these might be interchangeable. The bioassay method uses simple reagents, with minimum sample preparation 
procedures, generation of residues and it is less expensive than HPLC method, encouraging its application in routine analysis.

\section{Acknowledgements}

The authors are grateful to Maria de Fátima Rodrigues for technical support. This work was supported by CNPq - Brazil, CAPES - Brazil, and PADC - FCF - Araraquara Program.

\section{References}

[1] Vollmert C. and Behrendt H. (2005) Exp. Dermatol., 14, 215224.

[2] Leadersdorfer C.B., Kirkpatrick C.M.J., Kinzig-Schippers M., Bulitta J., Holzgrabe U., Drusano G.L. and Sörgel F. (2007) Antimicrob. Agents Chemother, 51, 3290-3297.

[3] Portuguese Pharmacopoeia 8th ed., (2005) Infarmed, Lisboa.

[4] British Pharmacopoeia (2010) Her Majesty's Stationery Office, London.

[5] European Pharmacopoeia, 7th ed. (2011) Strasbourg, France.

[6] Yasuda T. and Shimada S. (1971) J. Antibiot., 24, 290-293.

[7] Mohamed G.G. (2001) J. Pharm. Biomed. Anal., 24, 561-567.

[8] Al-Gannam S.M. (2002) Mikrochim. Acta, 138, 29-32.

[9] El Mammli M.Y. (2003) Spectrochim. Acta Part A 59, 771-776.

[10]Refat M.S and El Didamony A.M. (2006) Spectrochim. Acta Part A, 65, 732-741.

[11]Mohamed G.G, El Dien F.A.N. and Farag E.U. (2006) Spectrochim. Acta Part A, 65, 11-19.

[12]El Dien F.A.N, Mohamed G.G and Farag E.Y.Z.A. (2006) Acta Part A, 64, 210-215.

[13]Gujral R.S., Haque S.M. and Shanker P. (2009) J. Chem, 6, 397-405.

[14]Fiorentino F.A.M. and Salgado H.R.N. (2011) Current Pharm. Anal., 7, 268-276.

[15]Jacobs G.P, Dobrilovic L., Coombes R. and Raghavan N. (1986) Int. J. Pharm., 32, 151-158.

[16]Hung C.T, Lim J.K.C and Zoest A.R. (1988) J. Chromatogr, 425, 331-341.

[17]Grover M., Gulati M. and Singh S. (1988) J. Chromatogr. B 708, 153-159.

[18]Branch S.K., Casy A.F and Ominde E.M.A. (1987) J. Pharm. Biomed. Anal, 5, 73-103.

[19]Bodey G.P., Vallejos C. and Stewart D. (1972) Clin. Pharmacol. Ther., 13, 512-515.

[20]Thijssen H.H.W. and Mattie H. (1976) Antimicrob. Agents Chemother, 10, 441-446.

[21]Frank U., Schimidt-Eisenlohr B., Schlosser V., Spillner G., Schindler M. and Daschner F.D. (1988) Agents Chemother, 32, 930-931.

[22]Entenza J.M., Vouillamoz J., Glauser M.P. and Moreillon P. (1997) Antimicrob. Agents Chemother, 4, 1662-1667.

[23]Leder K., Turnidge J.D., Korman T.M. and Grayson M.L. (1999) J. Antimicrob. Chem., 43, 113-118.

[24]Paim C.S., Führ F., Barth A.B., Gonçalves C.E.I., Nardi N., Steppe M. and Schapoval E.E.S. (2011) Talanta 83, 17741779.

[25]Lopes C.C.G.O. and Salgado H.R.N. (2010) Talanta 82, 918922.

[26]Mendez A.S.L., Weisheimer V., Oppe T.P., Steppe M. and Schapoval E.E.S. (2005) J. Pharm. Biomed. Anal., 37, 649-
653.

[27]Salgado H.R.N., Lopes C.C.G.O. and Luchesi M.B.B. (2006) J. Pharm. Biomed. Anal., 40, 443-446.

[28]Moreno A.H. and Salgado H.R.N. (2007) J. AOAC Int., 90 (5), 1379-1382.

[29]Cazedey E.C.L. and Salgado H.R.N. (2011) Pharmaceutics, 3, 572-580.

[30]Brazilian Pharmacopoeia 5th ed. (2010) ANVISA, São Paulo, Brazil.

[31]The United States Pharmacopoeia, 31st ed. (2008), United States Pharmacopoeia Convention, Rockville, MD.

[32]Salgado H.R.N. and Tozo G.C.G. (2007) J. AOAC Int., 90 (2), $452-455$.

[33]AOAC International, Official Methods of Analysis, 18th ed. (2005) Gaithersburg, MD.

[34]ICH. (2005) International Conference on Harmonization of Technical Requirements for the Registration of Pharmaceutical for Human Use, Validation of Analytical Procedures, Text And Methodology - Q2(R1), Geneva.

[35]Hewitt W. (2003) Microbiological Assay for Pharmaceutical Analysis: a Rational Approach, Interpharm/CRC Press, Boca Raton, FL.

[36]Souza M.J.E., Rolim C.M.B., Melo J., Souza-Filho P.S. and Bergold A.M. (2007) J. AOAC Int., 90, 1724-1728. 